Forthcoming in: Psychiatry 8.12 (December 2009): 465-467.

\title{
Personal Autonomy and Mental Capacity
}

Fabian Freyenhagen (University of Essex)

Abstract: The Mental Capacity Act 2005 has put the assessment of mental capacity for decisionmaking at the forefront of psychiatric practice. This capacity is commonly linked within philosophy to (personal) autonomy, that is, to the idea(l) of self-government. However, philosophers disagree deeply about what constitutes autonomy. This contribution brings out how the competing conceptions of autonomy would play out in psychiatric practice, taking anorexia nervosa as a test case.

Keywords: mental capacity; autonomy; philosophy; anorexia nervosa; law; ethics; H. Frankfurt

Within philosophy, the concept of mental capacity for decision-making (or competence) is intimately connected to that of personal autonomy. In a nutshell, personal autonomy pertains to persons who govern themselves according to their own reasons or desires, where, depending on the particular view taken, this might include various emotive states, preferences, values, commitments, or character traits. While not without its critics, personal autonomy is widely valued in modern liberal societies and within philosophy. It is seen as the fundamental good that grounds moral and legal rights of individuals (including the right to refuse treatment), and whose violation constitutes (at least in part) the badness of domination, manipulation, paternalism, and slavery. Without personal autonomy, individuals are said to be at odds with themselves, not accountable, and unable to live authentic lives.

With so much at stake, it is perhaps unsurprising that there is no consensus among philosophers on the specific nature (and value) of autonomy. There are at least two deep fissures between rival and apparently incompatible ways of understanding autonomy.

The first fundamental disagreement is about whether or not autonomy is value-laden.

Often accounts of personal autonomy are value-neutral. In this case, a person's own reasons or desires need not be moral ones- he or she can be autonomous and non-moral or even immoral. 
However, there are also accounts which build values or the capacity to appreciate them directly into the conception of personal autonomy, though the values in questions need not be restricted to moral ones, but can include prudential values.

The second important dividing line within philosophical debates about personal autonomy, which partly cuts across the first one, is the issue of whether and to what extent autonomy must be rational. Thus, conceptions of autonomy differ as to whether or not the agent needs to meet certain requirements of rationality, and in their understanding of these requirements (formal/procedural versus substantive).

This contribution discusses three kinds of conceptions: (a) value-neutral, non-rational; (b) value-neutral, rational (procedural); and (c) value-laden, rational (substantive). It takes anorexia nervosa as a test case for each.

\section{Autonomy as reflective endorsement}

One prominent view among the theorists who argue for personal autonomy are higher-order accounts inspired by H. Frankfurt's influential discussion of freedom of the will. ${ }^{\mathrm{i}}$ On these accounts, we distinguish between first-order desires and second-order desires, that is, between wanting something and wanting to want it. Autonomy is then understood to require secondorder identification with those first-order desires that are effective in moving the will.

Conversely, one is lacking autonomy if one's effective first-order desires include wanting to do something which one does not want to want to do, such as in the case of an unwilling addict, who desires to take a drug, but does not identify with this desire and would prefer to be without it. Moreover, those who have no second-order desires at all (whom Frankfurt calls 'wantons') lack autonomy by default — given the structure of their desires (or rather, the lack of structure), they could not be autonomous.

This account of autonomy conceives of it neither in moral nor rational terms. While identification might acquire moral relevance-for example, it might suffice for moral 
responsibility - there is no internal link to morality implied in this structural constraint on an agent's motivational set. Thus, even someone who identifies with and endorses his or her immoral first-order desire counts as autonomous on this model. Similarly, autonomy does not necessarily involve meeting any rationality requirements - the reflective endorsement of firstorder desires at second-order level can be a wholly non-rational process. In fact, it need not even involve deliberation: second-order identification might be achieved even when the person in question did not consciously attend to the matter, but would endorse his or her first-order desires if he or she had attended to them.

One advantage of the Frankfurt-inspired model is that it seems to avoid the metaphysical commitments of many traditional models. It analyses autonomy (and personhood) in terms of something which is metaphysically innocuous, namely, in terms of a psychological capacity to hierarchically structure one's desires. By introducing the idea of a hierarchy of desires we can explain the resolution of conflicts among first-order desires by appeal to a 'true self', but without commitment to a homunculus or transcendental self. Other advantages are that this model need not conceive of emotions as alien influences, and that it frees autonomy from overly evaluative and moralised presuppositions. For these reasons, this model may seem promising for deployment in psychiatric practice.

However, there are also problems with this model. Leaving aside the philosophical debates surrounding it, we can see this by considering the test case of anorexia nervosa. Persons who have anorexia often see it as part of their personal identity. if If this means that they reflectively endorse it, then they would count as autonomous on the Frankfurt-inspired model and be entitled to the full legal protection of their choices. In fact, even if the second-order identification with the first-order desire to be thin at all costs is shown to have its origin in the condition, this would not suffice to discount it as inauthentic on this model. However, most psychiatrists tend to think that anorexia nervosa impedes mental capacity and, in any case, may merit compulsory treatment. i.i Hence, this model is in conflict with contemporary psychiatric 
practice, and one of the two would have to give way.

\section{Autonomy as procedural independence}

One influential alternative adds a constraint to the Frankfurt-inspired model of personal autonomy: if the process of identification with first-order desires was affected by autonomyundermining influences, then the identification is not counted as conferring autonomy. ${ }^{\text {iv }}$ In this way, a rationality constraint of a procedural nature is included into the conception. The crucial challenge for the proponents of this alternative model is to identify which influences are autonomy-undermining and which are not, and to identify them on the basis of a procedural account alone, without reference to objective reasons or the rationality of outcomes. Only if this challenge can be successfully met is this model truly value-neutral, which would have the advantage of making autonomy compatible with the entrenched value pluralism of modern liberal societies.

However, it is far from obvious that procedural independence suffices to identify all intuitively autonomy-undermining influences and conditions. The standard of rationality employed here is minimal and only concerns the process of reasoning-beliefs and desires need to be in some sort of coherence and this coherence should not be the result of factors which inhibit or outweigh reasoning processes in a problematic way (with the paradigm examples being manipulation by others and lack of certain cognitive faculties). Yet, there are some cases in which such a minimal, procedural standard of rationality is met, but we would still not want to call the person autonomous, or attest them mental capacity. Thus, there may be some patients who, while otherwise in possession of their cognitive abilities, have a set of delusional or false beliefs and/or distorted values, but reason as well on the basis of these beliefs or values as nonpathological persons do (and also achieve similar or higher levels of coherence). In fact, it has been shown that anorexia patients often display neither below-average defects in cognitive ability, nor a lack of coherence-just the opposite: many have hierarchically organised value systems 
and perform well in terms of reasoning, understanding, and expressing their choices. ${ }^{\mathrm{v}}$ On the procedural rationality model these patients would again count as autonomous and, hence, be granted the full legal right of self-determination. Yet, this seems counterintuitive and, as seen, contravenes psychiatric practice.

\section{Autonomy as responsiveness to reasons}

Considerations such as these might motivate the turn to yet a third model of personal autonomy, according to which we need to add a different sort of criterion: responsiveness to 'objective reasons'. Such reasons might be of a cognitive nature, so that responsiveness to them implies that one is not completely ignorant or has no manifestly false and delusional beliefs; ${ }^{\text {vi }}$ or these reasons can (also) involve orientation by and appreciation of values. ${ }^{\text {vii }}$ If so, then personal autonomy gains an inherently value-laden, sometimes even moral, dimension. Thus, Meyers, among others, claims that the conduct of the agent needs to be within the bounds of the morally permissible to count as (genuinely) autonomous. viii Kant and Kantians go further still: for them autonomy amounts to agents self-legislating the moral law and acting out of respect for it. ${ }^{\mathrm{ix}}$

On the third model, patients with anorexia nervosa would most likely not be counted as autonomous, for they often have false beliefs about how thin they are; their paramount regard for thinness would be faulted for showing insufficient appreciation of the value of their health, life, and relationships; and they could be seen as treating their own agency as a means to a nonmoral end that endangers their moral agency. Hence, they would be judged to lack mental capacity or, at any rate, autonomy, and could legitimately be treated for their condition, even when they do not consent to such treatment.

However, this assessment comes at a cost: adopting this third model of autonomy would mean that psychiatry will not be completely value-neutral or value-free. Also, difficulties arise because there is deep, and arguably, reasonable pluralism about values and the nature of substantive rationality within modern societies. Conceptions of autonomy which contain a 
substantive rationality standard will thus face the challenge of being sufficiently broad to be compatible with this pluralism, but also sufficiently fine-grained to be of use in identifying lack of capacity in psychiatric and legal contexts. Moreover, such conceptions are in tension with an intuition which is widely accepted in modern, liberal societies: most adult human beings are selfgoverning their lives to an extent that they should be granted the full right of self-determination, despite the fact that they often do not meet standards of substantive rationality. In fact, respect for individual autonomy within liberal states includes the legal protection of irrational, 'unwise' choices.

\section{Conclusion}

The Frankfurt-inspired model of autonomy might seem attractive for psychiatric practice, but suffers from the fact that its criterion for autonomy (reflective endorsement) does not suffice to exclude many cases where mental capacity and autonomy is (seen to be) compromised. Use of conceptions of autonomy which build in rationality of either a procedural or substantive kind are more promising for establishing mental capacity, since these conceptions offer more guidance than the Frankfurt-inspired model. Still, we have seen that they do not fit clinical and legal practices, since anorexic patients are not treated as autonomous even when procedurally rational and (substantively) irrational decisions can be protected by the law. Thus, before either of these philosophical conceptions can be utilised in the clinical or legal context, further refinements both within and between law, philosophy, and psychiatry will be required. ${ }^{\mathrm{x}}$

One salient aspect of contemporary philosophical debates not yet touched upon is the question of the appropriate unit for autonomous choice: while in antiquity autonomy was predominantly used to describe city states, it now tends to be applied to individuals. Recently, relational accounts of autonomy have proposed to widen the perspective to the social context of choice, ${ }^{\mathrm{xi}}$ and this could also have implications for the way mental health care professionals assess mental capacity. 
Contact details: Dr. Fabian Freyenhagen, Department of Philosophy, University of Essex, Wivenhoe Park, Colchester, CO4 3SQ, UK. Email: ffrey@essex.ac.uk

i Frankfurt, H. Freedom of the will and the concept of the person. Journal of Philosophy 1971, 68.1: 5-20.

ii Tan, J.O.A., Stewart, A., Fitzpatrick, R. \& Hope, T. Competence to Make Treatment Decisions in Anorexia Nervosa: Thinking Processes and Values. Philosophy, Psychiatry, \& Psychology 2006, 13.4: 267-282, especially 276.

iii Tan, J.O.A., Doll, H.A., Fitzpatrick, R., Stewart, A. \& Hope, T. Psychiatrists' attitudes towards autonomy, best interests and compulsory treatment in anorexia nervosa: a questionnaire survey. Child and Adolescent Psychiatry and Mental Health 2008, 2: 40.

iv Dworkin, G. The Concept of Autonomy. In R. Haller, ed. Science and Ethics. Amsterdam: Rodopi Press, 1981.

v Tan, Stewart, Fitzpatrick \& Hope op. cit. note 2.

vi See, for example, Berofsky, B. Liberation from Self: A Theory of Personal Autonomy. Cambridge: Cambridge University Press, 1995.

vii Benson, P. Freedom and Value. Journal of Philosophy 1987, 84.9: 465-486.

viii Meyers, D.T. Self, Society, and Personal Choice. New York: Columbia University Press, 1989.

ix O'Neill, O. Autonomy: The Emperor's New Clothes. Proceedings of the Aristotelian Society, Supplementary Volume 2003, 77.1: 1-21.

x Owen, G., Freyenhagen, F., Richardson, G. \& Hotopf, M. Mental Capacity And Decisional Autonomy: An Interdisciplinary Challenge. Inquiry 2009, 52.1: 79-107.

xi See, for example, Meyers op. cit. note 8; Oshana, M. Personal Autonomy and Society. Journal of Social Philosophy 1998, 29.1: 81-102; MacKenzie, C. and Stoljar, N. (eds.). Relational Autonomy: Feminist Perspectives on Autonomy, Agency, and the Social Self. Oxford: Oxford University Press, 2000.

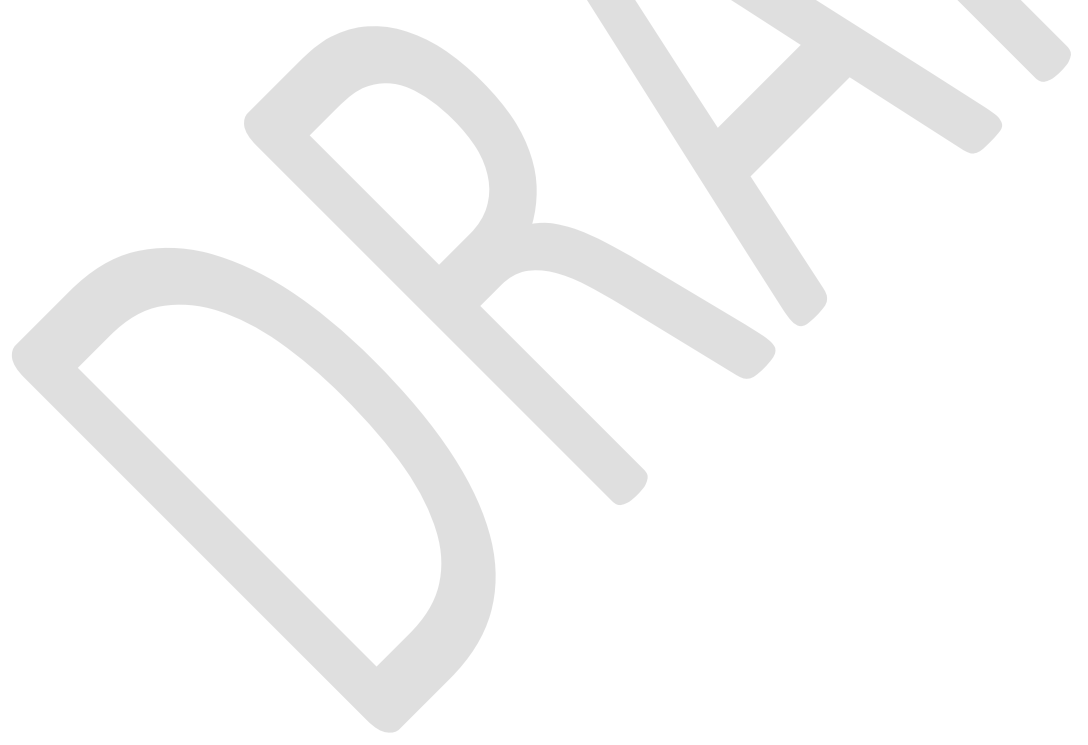

